\title{
Association Between Sexual Problems and Relationship Satisfaction Among People With Cardiovascular Disease
}

Molly Byrne, Patrick Murphy, Maureen DEath, Sally Doherty and Tiny J aarsma

The self-archived version of this journal article is available at Linköping University Electronic Press:

http:/ / urn.kb.se/ resolve?urn=urn:nbn:se:liu:diva- 139412

N.B.: When citing this work, cite the original publication.

Byrne, M., Murphy, P., DEath, M., Doherty, S., J aarsma, T., (2017), Association Between Sexual Problems and Relationship Satisfaction Among People With Cardiovascular Disease, J ournal of Sexual Medicine, 14(5), 666-674. https:// dx.doi.org/ 10.1016/j.jsxm.2017.03.252

Original publication available at:

https:/ / dx.doi.org/ 10.1016/j.jsxm.2017.03.252

Copyright: Wiley: 12 months

http:// eu.wiley.com/WileyCDA/ 
Running Head: CVD, sex and relationship satisfaction

\section{Title Page}

Title

Association between sexual problems and relationship satisfaction among people with cardiovascular disease. 
Running Head: CVD, sex and relationship satisfaction

\begin{abstract}
Background: Relationship satisfaction is generally positively correlated with sexual satisfaction, but this relationship has been poorly examined among people with cardiovascular disease, who are at increased risk of sexual problems when compared to the general population.

Aim: To (1) document reported changes to sex following a diagnosis of cardiac disease and (2) determine if there is an association between sexual function and relationship satisfaction.

Methods: Semi-structured telephone interviews focused on relationship satisfaction and sexual problems were conducted with 201 people with cardiovascular disease who were currently in a sexual relationship with one main partner, recruited from six hospital cardiac rehabilitation centres in Ireland. Comparisons between groups were conducted using $t$-tests and MANOVA for continuous variables, and $\chi 2$ tests for categorical variables. Predictors of relationship satisfaction were assessed using multiple linear regression.
\end{abstract}

Outcomes: Data were gathered on: demographic and clinical variables, sexual problems, and relationship satisfaction, including satisfaction with the physical, emotional, affection and communication aspects of relationships.

Results: Just under one third of participants ( $n=61,30.3 \%)$ reported that sex had changed for the worse since their cardiac event or diagnosis, with about half of these stating that this was a serious problem for them. Satisfaction with relationships was high among patients surveyed; over $70 \%$ of the sample reported being very or extremely satisfied with physical aspects, emotional aspects and showing affection during sex. Satisfaction with communication around sex was lower, with only 58\% reporting being very or extremely 
Running Head: CVD, sex and relationship satisfaction

satisfied. We did not find significant associations between reporting of sexual problems, or deterioration of sex as a result of disease, and relationship satisfaction.

Clinical Implications: Cardiac rehabilitation programmes should address these sexual problems, potentially by enhancing communication between couples about sex.

Strengths and Limitations: Our strength is that we present data on the sexual experiences and relationship satisfaction of a relatively large sample of people diagnosed with cardiac disease, a relatively underexplored research area. Limitations include the possibility of selection bias of study participants and bias associated with self-report measurement.

Conclusions: Sexual problems are significant among this population, but in our crosssectional survey they were not related to relationship satisfaction.

\section{Keywords}

(4-6 keywords required)

Cardiovascular diseases, sexual dysfunction, cardiac rehabilitation, relationship satisfaction, cardiac rehabilitation

\section{Take home message}

Sexual problems are significant among an Irish sample with coronary heart disease, but not related to relationship satisfaction, which is generally high. Cardiac rehabilitation should support patients to address sexual problems, perhaps by enhancing couples' ability to communicate about sex. 
Running Head: CVD, sex and relationship satisfaction

\section{Introduction}

It is commonly believed that the quality of a couple's relationship and the quality of their sex life are linked (1). However, the verity of this association is a matter of debate $(2,3)$.

Communication within couples appears to be important to both sexual and relationship satisfaction. In a study of 387 couples, communication and sexual satisfaction independently predicted marital satisfaction (4). An interesting significant interaction between communication and sexual satisfaction was observed in this study: if couples were successful at communicating constructively, sexual satisfaction failed to contribute to marital satisfaction. Couples who reported difficulty with communication, but who were sexually satisfied, reported greater marital satisfaction than those with a less satisfying sexual relationship. Thus, the authors concluded that sexual satisfaction may partially compensate for the negative effects of poor communication on marital satisfaction. Equally, good communication may reduce the impact of sexual dissatisfaction on marital satisfaction. Effective sexual communication has been found to be important to sexual relationship satisfaction (5). Couples who maintain a high quality of communication about sex are more likely to have a satisfying sexual relationship (3).

Byers (3) has suggested that, although there appears to be some evidence for the link between greater relationship satisfaction and greater sexual satisfaction, assumptions about this association have been too simplistic to date. She suggests that the nature of the relationship between these two variables varies according to a number of factors, including situational and context factors in which the relationship exists.

One such factor may be the presence of a chronic illness. Sexuality and sexual function are often affected in individuals living with chronic illness and their partners, and 
Running Head: CVD, sex and relationship satisfaction

multiple comorbidities increase the likelihood of sexual dysfunction (6). Social support and strong intimate relationships are important predictors of outcomes for chronic illness patients and marital quality has been shown to predict patient mortality (7).

People with cardiovascular disease, for example, are more likely to report sexual problems than individuals without disease (8-11). For example, prevalence rates for sexual problems among Irish sexually active men with cardiovascular disease were $47 \%$ and for women, 37\% (12), nearly double rates for an age-matched general population sample (13), in line with findings from other countries (14). Reasons for the association between sexual problems and cardiovascular disease include physical vascular causes (15), fear of sexual activity provoking cardiac symptoms or a cardiac event (16), patient/partner relationship changes following a cardiac event (17) and associations with psychological problems such as depression and the burden of being diagnosed with a chronic illness (18).

Sexual problems can impact on a range of aspects of people's lives. They have been associated with lower levels of quality of life and higher levels of anxiety and depression (12, 18) among people with cardiac disease. Sexual problems also impact cardiac patients’ partners, who rate sexual concerns as one of the most prevalent stressors (19).

The association between sexual problems and relationship quality among people with cardiovascular disease has been relatively under-researched. In a previous study, people with cardiac disease who reported sexual problems reported significantly lower partnership satisfaction (more quarrelling, less tenderness, less communication, as well as significantly lower quality of partnership overall), compared with people without sexual problems (20). In another study of people with cardiac disease, researchers reported 'a mild to moderate association between sexual relation and marital quality' among the study sample (2). They 
Running Head: CVD, sex and relationship satisfaction

reported that different patterns were observed based on gender, education level, and marital distress level and concluded that the association between sexual function and marital relationship quality in cardiac patients requires further investigation.

Therefore, in this paper we aim to answer the following research questions for a sample of cardiac patients who reported being in a relationship with one main partner:

1. Do people report changes to their experience of sex following a diagnosis of heart disease?

2. In what ways do patients perceive their heart disease affects their sex life?

3. How satisfied are cardiac patients with their relationships (on the following dimensions: physical, emotional, affection, communication about sex)?

4. Is there an association between the impact of a cardiac event on sex and relationship satisfaction? (physical, emotional, affection, communication about sex)? Is this relationship different for men and women? Does this relationship differ depending on age?

5. Is there an association between sexual function problems (after diagnosis/coronary event) and satisfaction with relationships among CVD patients (physical, emotional, affection, communication about sex)? Is this relationship different for men and women? Does this relationship differ depending on age?

\section{Methods}

\section{Design}

A cross-sectional telephone survey of people with coronary heart disease who attended cardiac rehabilitation services in the Republic of Ireland was conducted between June 2010 and August 2011. Ethical approval for the study was obtained from the Research 
Running Head: CVD, sex and relationship satisfaction

Ethics Committee of the National University of Ireland, Galway and from each participating hospital. For a more detailed description of the method for this study, see Byrne et al (8).

\section{Participant Recruitment and Procedure}

Participants were recruited from 6 hospital-based cardiac rehabilitation units in the Republic of Ireland. Participants were included in the survey if they were over the age of 18, and had attended cardiac rehabilitation services within the two months prior to data collection. Only participants who reported that they were in a sexual relationship with one main partner at the time of data collection were included in the current analysis. All patients without a record of death, meeting the inclusion criteria within participating centres were mailed a letter of invitation to participate. If they did not opt-out of the study by return of a prepaid card, they were contacted by phone by a researcher within $2-4$ weeks. The researcher addressed any questions and verbal consent to participate was sought over the phone before commencing each interview. All telephone interviews were conducted by one of the authors (SD) between June 2010 and August 2011.

\section{Measures}

Demographic and clinical data. Participants specified: gender, age, educational level, marital status, medical diagnoses, previous cardiac procedures, and the use (yes/no) of medication to increase sexual function.

Sexual activity. Participants specified the number of sexual partners they had in the last year (response options were $0,1,2$, 3, or more than 3 ), frequency of sexual activity in the last year (response options were 0, less than once a month, once or twice a month, once or twice a week, twice or three times a week, more than three times a week) and in the last 4 
Running Head: CVD, sex and relationship satisfaction

weeks (response options were 0 , less than once a week, once or twice a week, twice or three times a week, four to six times a week, at least once a day).

Sexual Problems. Participants were asked whether they had experienced (yes/no) any of the following sexual problems for a period of 1 month or more in the twelve months since their coronary event or procedure: lacked interest in sex, did not find sex pleasurable, unable to climax, climaxed too quickly (men only), trouble maintaining an erection (men only), physical pain during intercourse, trouble becoming lubricated (women only), feeling anxious about ability to perform, and other (asked to specify).

Changes in sex since cardiac event/procedure. Participants were asked whether sex had changed for them since their cardiac event or procedure (response options: yes, for the better; yes, for the worse; no). Those who indicated that sex had changed were asked to provide more detail in their own words. Finally, those who reported a deterioration in sex were asked to rate how serious a problem this was for them, on a 4-point Likert scale ranging from a very serious problem to not really a problem at all.

Relationship satisfaction. Participants were asked to rate their satisfaction with their relationship in terms of physical pleasure, emotional satisfaction, displaying affection, and communication. Responses were indicated on a 5-point Likert scale ranging from extremely satisfied to not at all satisfied.

\section{Analysis}

Quantitative data were analysed using SPSS v23. Participants were grouped according to their perceived change in sex since diagnosis or cardiac events (i.e. change for the better, change for the worse, no change, not sure), and compared as to their reported relationship 
Running Head: CVD, sex and relationship satisfaction

satisfaction (physical, emotional, affection, communication) using multivariate analysis of variance (MANOVA). Participants were grouped according to whether they reported at least one sexual function problem in the 12 months after their cardiac event or procedure, and then compared as to their reported relationship satisfaction (physical, emotional, affection, communication) using independent samples $t$-tests. The cumulative number of sexual problems reported, gender, and age were assessed as predictors of the domains of relationship satisfaction using multivariate multiple regression

Participants who reported that sex had changed either for better or for worse since their cardiac event were invited to elaborate on their answer. These short, free text responses were inputted into SPSS by the researcher (SD) at the time of the interviews. The responses were subsequently extracted from SPSS into a Microsoft Word document, subjected to content analysis by the second researcher (MD), and hence collated under the headings presented below which were agreed by all members of the research team.

\section{Results}

\section{Demographic and Medical Characteristics}

Semi-structured telephone interviews were conducted with 382 people with cardiovascular disease (32\% response rate) recruited from six hospital cardiac rehabilitation centres. Two-hundred and one participants who reported that they were in a sexual relationship with one main partner at the time of data collection were included in the current analysis. Demographic and medical characteristics for the sample are shown in Table 1.

Most participants were male ( $n=176,87.6 \%)$, were between 50 and 70 years old ( $M$ $=60.9, S D=9.6)$, had completed at least secondary education $(n=149,74.1 \%)$, and were 
Running Head: CVD, sex and relationship satisfaction

married $(n=186,92.5 \%)$. The most common medical diagnoses were high cholesterol $(n=$ 130, 64.7\%), myocardial infarction ( $n=112,55.7 \%)$, and high blood pressure $(n=105$, 52.2\%). The majority of patients had undergone stenting ( $n=142,70.6 \%)$, with other medical procedures being far less frequently reported. A sizeable minority reported the use of medication to improve sexual function since their cardiac event or procedure ( $n=46,22.9 \%)$. When demographic and medical characteristics were compared across genders, it was found that men were statistically more likely to have a diagnosis of diabetes $\left(X^{2}[2,210]=5.81, p<\right.$ $.05)$ and to use sexual function medication $\left(X^{2}[2,210]=5.77, p<.05\right)$, while women were more likely to have a diagnosis of anxiety $\left(X^{2}[2,210]=7.98, p<.05\right)$. No other significant differences were found across gender.

\section{[INSERT TABLE 1 HERE]}

\section{Sexual Activity and Sexual Problems}

Of the 201 participants in the sample, 198 (98.5\%) reported only 1 sexual partner in the previous year. When asked to recall the frequency of sexual activity in the previous year, 126 (62.7\%) participants reported having sex at least monthly, 68 (33.8\%) reported having sex less often than monthly, and only 2 reported no sexual activity. When asked to recall the frequency of sexual activity in the last 4 weeks, 134 (66.6\%) reported having sex at least once, with 64 (31.8\%) reporting no sexual activity.

The prevalence of sexual problems are reported below in Table 2. For men the most commonly reported sexual problem was trouble maintaining an erection, which affected 1 in 3 men after their diagnosis or cardiac event. For women the most commonly reported problem was lack of interest in sex, although this was reported by many men also. Both 
Running Head: CVD, sex and relationship satisfaction

genders frequently reported that they could not come to orgasm, with close to 1 in 5 participants affected by this problem.

[INSERT TABLE 2 HERE]

\section{Research Question 1. Do people report changes to their experience of sex following a diagnosis of heart disease?}

Just under one third of participants ( $n=61,30.3 \%)$ reported that sex had changed for the worse since their cardiac event or diagnosis. When sex had worsened there was variability in how that was experienced by participants, with about half reporting that it was a very or somewhat serious problem $(n=29)$, and about half reporting that is was a minor problem or not problematic $(n=32)$. Twenty-three participants $(11.4 \%)$ said that sex had changed for the better since their diagnosis of CHD.

\section{Research Question 2. In what ways do patients perceive their heart disease affects their sex life?}

Sixty-three (59\%) of the participants who reported that sex, for them, had changed since their cardiac event expanded on their response. These responses give an interesting insight into the impact of a diagnosis of CHD on sexual activity. Forty-three of these sixtythree (68\%) participants reported that sex had changed for the worse. These responses were collated under the headings of physical problems, psychological problems, medication issues and relationship difficulties, with some patients citing more than one of these difficulties.

Thirteen (30\%) of the forty-three patients for whom sex was more problematic cited medication as the source of their sexual difficulty; two of these (15\%) specified the problematic medication as beta blockers. Five of the forty-three patients (12\%) specified that 
Running Head: CVD, sex and relationship satisfaction

they had erection problems and three of these five patients (60\%) linked the problem to their medications.

Two patients (5\%) considered that sex had worsened for them due to their age and another said that he did not know why he was less sexually active. The psychological problems identified by the patients largely focussed on fear and anxiety with nine patients (21\%) citing this as important. Such fear and anxiety included lack of confidence, fear of resuming sexual activity, worry about performance and fear of over-exertion. One patient (2\%) identified that they were suffering from depression and one patient's fear was specifically of dying during sex and the 'shame' that would be associated with such a death. Two patients (5\%) stated that their partner's fear or anxiety was the cause of the deterioration in their sex life.

Lack of energy was the main physical challenge to patients' engagement in sexual activity since their diagnosis of cardiac ill health (9 of the 43 (21\%) patients reporting that sex was worse cited this as important). Many of the patients who cited lack of energy were also among those who stated that they were experiencing a loss of interest in sex and/or a loss of libido (6 (14\%) identified this as an issue).

The partner of one patient was suffering from ill health which impacted on their sexual relationship.

Of the twenty-three patients who indicated that sex had improved since their cardiac event or procedure, twenty (87\%) elaborated on their response. Two (10\%) of these twenty people identified that the improvement was due to taking medication to enhance sexual function (Sildenafil) and one (5\%) that the improvement was due to having more time for 
Running Head: CVD, sex and relationship satisfaction

sex. A number related the improvement to a new appreciation of life "feel like I have a new lease of life", a more relaxed approach to life "take it easy, live in the moment" or improved fitness levels “feel better in yourself, keep fit, walk every day”. Seven of the participants (35\%) cited that their improved energy levels following cardiac interventions had contributed to an improved sex life.

\section{Research Question 3. How satisfied are cardiac patients with their relationships (on the} following dimensions: physical, emotional, affection, communication about sex)?

Satisfaction with relationships was high among patients surveyed. Most patients reported that they found sex with their partners to be extremely or very pleasurable $(n=153$, 76.1\%), that their relationships were extremely or very emotionally satisfying $(n=154$, 76.7\%), that they were extremely or very satisfied with how they and their partner showed affection during sex ( $n=147,73.2 \%)$, and that they were extremely or very satisfied with the way in which they and their partner communicated about sex ( $n=117,58.2 \%)$. (Table 3).

When comparing responses by gender, sex was rated as less physically pleasurable by women $(M=3.44, S D=1.19)$ than by men $(M=4.10, S D=0.87) ; t=-3.36, p<.05$. No other significant differences were found.

[INSERT TABLE 3 HERE]

Research Question 4. Is there an association between the impact of a cardiac event on sex and relationship satisfaction? (physical, emotional, affection, communication about sex)? Is this relationship different for men and women? Does this relationship differ depending on age?

Multivariate analysis of variance (MANOVA) revealed no significant differences in relationship satisfaction scores across groups. Data are presented below in Table 4. Given the 
Running Head: CVD, sex and relationship satisfaction

lack of a statistically significant relationship, mediation/moderation by gender or age were not tested for.

[INSERT TABLE 4 HERE]

Research Question 5. Is there an association between sexual function problems (after diagnosis/coronary event) and satisfaction with relationships among CVD patients (physical, emotional, affection, communication about sex)? Is this relationship different for men and women? Does this relationship differ depending on age?

Independent samples $t$-tests revealed no differences in relationship satisfaction scores across groups (reported at least one sexual function problem versus none). Data are presented below in Table 5. Given the lack of a statistically significant relationship, mediation/moderation by gender or age were not tested for.

[INSERT TABLE 5 HERE]

The cumulative number of sexual problems reported, gender, and age were assessed as predictors of the domains of satisfaction using multivariate multiple regression (see Table 6). Only the model for physical pleasure was found to be significant, $F(3,192)=7.47, p<$ .00. In this model, the cumulative number of sexual problems was not a significant predictor of physical pleasure, but both gender $(\beta=-.73, t(195)=-3.87, p<0.05)$ and age $(\beta=-.02$, $t(195)=-2.46, p<.05)$ were significant predictors. Both being female and being older predicted lower physical satisfaction.

[INSERT TABLE 6 HERE] 
Running Head: CVD, sex and relationship satisfaction

\section{Discussion}

Overall in our sample of people with cardiac disease, largely older (aged between 50 - 70 years), male and all with one regular sexual partner, participants reported relatively infrequent sexual activity (the majority reported once monthly or less frequently).

We previously reported high levels of sexual problems among a sample of people with cardiac disease (8), with nearly half of sexually active respondents indicating at least one sexual problem. In the current paper, we report that levels of sexual problems are high both before and after a cardiac diagnosis or event. Indeed, a number of participants report some improvements in 'softer' markers of sexual function, such as: 'Lacked interest in having sex' or 'Did not find sex pleasurable'. It is possible that participants experienced more symptoms before their cardiac diagnosis, such as more chest pain and fatigue. After the event, these symptoms may have been reduced by taking medications or undergoing treatments, such as Percutaneous Coronary Intervention (PCI) or Coronary Artery Bypass Grafting (CABG).

In our sample, roughly a third of participants reported that sex had changed for the worst, with about half of this group stating that this was a serious problem for them. Perceived reasons for this decline in sex following their diagnosis with cardiac disease included issues with cardiac medications, feeling tired, lacking energy, losing interest in sex and fears and anxieties including lack of confidence, fear of resuming sexual activity, worry about performance and fear of over-exertion. A smaller group (11\%) reported that sex had improved for them following their diagnosis, citing reasons such as taking medication to enhance sexual function and generally feeling better, most likely following effective intervention. 
Running Head: CVD, sex and relationship satisfaction

Interestingly, satisfaction with relationships in this sample appeared to be relatively high; over $70 \%$ of the sample reported being very or extremely satisfied with physical aspects, emotional aspects and showing affection during sex. Satisfaction with communication around sex was lower, with only 58\% reporting being very or extremely satisfied with this aspect of the relationship. Efforts to enhance communication skills to enable couples to talk about sex, including any experience of sexual problems, may be useful to support people with cardiac disease to resume sexual activity after a cardiac event or procedure, and promote relationship satisfaction among those with lower levels.

We did not find associations between reporting a deterioration in sex following diagnosis and relationship satisfaction, or between reporting of sexual problems and relationship satisfaction. This may mean that in this sample, of largely older married men with a diagnosis of cardiac disease, sexual problems did not impact on relationship satisfaction. Other research has shown that even when couples find a cardiac event distressing, they generally manage to adjust their relationship to the new situation (17). Our findings are cross-sectional and are limited in informing us about the causal relationships between these variables. Future research should focus on determining if interventions can effectively reduce sexual problems and enhance relationship satisfaction among this population. Previous studies have demonstrated that by reducing sexual dysfunction, the perceived quality of partnerships can be enhanced (21).

It is also possible that our findings may reflect a measurement problem. In an interesting study by Hicks and colleagues (22) they found that sexual frequency among couples was related to automatic partner evaluations (as measured using a laboratory-based priming task to measure their automatic attitudes to their partners), but not explicit marital 
Running Head: CVD, sex and relationship satisfaction

satisfaction (a standard marital satisfaction questionnaire). It may be possible that deliberate reasoning processes which are called into action when we are asked to think about questions about our relationships, may be a less accurate measure of our attitudes to our partners than automatic evaluations.

\section{Limitations}

A central problem is a possible selection bias of study participants. Responders in our study may have differed in significant ways to non-responders. Responders may be more interested in sexual matters than non-responders. Our sample is made up of predominantly older men. Issues related to sexuality and relationships are likely to differ across the lifespan; future research focusing in particular on the experience of younger people would be valuable. As data were collected from patients themselves, rather than clinical records, our clinical data are somewhat limited and it is possible that some of the clinical data are inaccurate, due to inaccurate beliefs, information or understanding of the clinical conditions by patients. Also, we did not collect data on the full range of cardiac clinical conditions, such as whether patients had valvular heart disease, heart failure or cardiomyopathy.

Self-reports of sexual behaviour may be inaccurate, and can be influenced by a number of factors including recall errors, social desirability and impression management (23). In addition, some of our data were collected using non-validated tools.

It is possible that our participants have under-represented their dissatisfaction with sexual aspects of their lives. It is not easy to reveal unhappiness and dissatisfaction in sexual life, to admit that one has failed in this central area of life (24). 
Running Head: CVD, sex and relationship satisfaction

\section{Conclusion}

In summary, we did not find a strong relationship between sexual problems or deterioration of sex as a result of disease and satisfaction with other aspects of relationships: physical satisfaction, emotional satisfaction, satisfaction with how emotion is expressed or communication satisfaction. However, we have reported relatively high levels of sexual function problems, and a sizeable minority who report finding their sexual problems distressing and a cause for worry. Cardiac rehabilitation programmes should address sexual problems and support people in returning to sexual activity. These programmes should include strategies to promote good communication between couples about sex.

\section{Acknowledgements}

We acknowledge the valuable input of patients and participating hospitals, and all members of the CHARMS Study Steering Committee, which also included: Prof Andrew Murphy and Ms Kate O’ Donovan. This work was supported by the Health Research Board (Ireland) grant number: RP/2007/124).

\section{Conflict of Interest}

None to declare.

\section{Statement of Authorship}

\section{Category 1:}

a) conception and design: $\mathrm{MB}, \mathrm{PM}, \mathrm{MD}$

b) analysis of data: $\mathrm{PM}, \mathrm{MD}, \mathrm{SD}$

c) interpretation of data: $\mathrm{MB}, \mathrm{PM}, \mathrm{MD}, \mathrm{SD}, \mathrm{TJ}$

Category 2: 
Running Head: CVD, sex and relationship satisfaction

a) drafting the article: $\mathrm{MB}, \mathrm{PM}, \mathrm{MD}$

b) revising it critically for important intellectual content: $\mathrm{MB}, \mathrm{PM}, \mathrm{MD}, \mathrm{SD}$, TJ

Category 3

a) final approval of the version to be published: $\mathrm{MB}, \mathrm{PM}, \mathrm{MD}, \mathrm{SD}, \mathrm{TJ}$ 
Running Head: CVD, sex and relationship satisfaction

\section{References}

1. Wincze JP, Carey MP. Sexual dysfunction: A guide for assessment and treatment. New York: Guilford; 2001.

2. Assari S, Moghani Lankarani M, Ahmadi K, Kazemi Saleh D. Association between Sexual Function and Marital Relationship in Patients with Ischemic Heart Disease. The Journal of Tehran University Heart Center. 2014;9(3):124-31.

3. Byers ES. Relationship satisfaction and sexual satisfaction: A longitudinal study of individuals in long-term relationships. The Journal of Sex Research. 2005;42(2):113-8.

4. Litzinger S, Coop Gordon K. Exploring Relationships Among Communication, Sexual Satisfaction, and Marital Satisfaction. Journal of Sex \& Marital Therapy. 2005;31(5):409-24.

5. Byers ES, Demmons S. Sexual satisfaction and sexual self-disclosure within dating relationships. The Journal of Sex Research. 1999;36(2):180-9.

6. Steinke EE. Sexuality and Chronic Illness. . Journal of Gerontological Nursing 2013;39(11):18-

27.

7. Coyne JC, Rohrbaugh MJ, Shoham V, Sonnega JS, Nicklas JM, Cranford JA. Prognostic importance of marital quality for survival of congestive heart failure. The American Journal of Cardiology. 2001;88(5):526-9.

8. Byrne M, Doherty S, Murphy AW, McGee HM, Jaarsma T. The CHARMS Study: cardiac patients' experiences of sexual problems following cardiac rehabilitation. European Journal of Cardiovascular Nursing. 2013;12(6):558-66.

9. Schumann J, Zellweger MJ, Di Valentino M, Piazzalonga S, Hoffmann A. Sexual Dysfunction before and after Cardiac Rehabilitation. Rehabilitation Research and Practice. 2010;Article ID 823060:10.1155/2010/823060.

10. Schwarz ER. Sexual dysfunction and its relation to heart disease (Editorial). International Journal of Impotence Research. 2005;17(S1):S1-S3.

11. Kütmeça C, Yurtseverb S. Effects of sexual function of essential hypertensions in women. European Journal of Cardiovascular Nursing. 2011;10(1):56-63.

12. Byrne M, Doherty S, Murphy AW, McGee H, Jaarsma T. The CHARMS Study: Cardiac patients' experiences of sexual problems following cardiac rehabilitation. European Journal of Cardiovascular Nursing. 2013.

13. Layte R, McGee HM, Quail A, Rundle K, Cousins G, Donnelly C. The Irish Study of Sexual Health \& Relationships. Dublin; 2006.

14. Traeen B, Olsen S. Sexual dysfunction and sexual well-being in people with heart disease. Sexual \& Relationship Therapy. 2007;22(2):193-208.

15. Dong J-Y, Zhang Y-H, Qin L-Q. Erectile Dysfunction and Risk of Cardiovascular Disease: MetaAnalysis of Prospective Cohort Studies. Journal of the American College of Cardiology. 2011;58(13):1378-85.

16. Katz A. Sexuality and myocardial infarction. AmericanJournal of Nursing. 2007;107(3):49-52.

17. Dalteg T, Benzein E, Fridlund B, Malm D. Cardiac disease and its consequences on the partner relationship: A systematic review. European Journal of Cardiovascular Nursing. 2011;10(3):140-9.

18. Kriston L, Gunzler C, Agyemang A, Bengel J, Berner MM. Effect of sexual function on healthrelated quality of life mediated by depressive symptoms in cardiac rehabilitation: Findings of the SPARK project in 493 patients. Journal of Sexual Medicine. 2010;7(6):2044-55.

19. O'Farrell P, Murray J, Hotz SB. Psychologic distress among spouses of patients undergoing cardiac rehabilitation. Heart \& Lung. 2000;29(2):97-104. 
Running Head: CVD, sex and relationship satisfaction

20. Gunzler C, Kriston L, Harms A, Berner MM. Association of sexual functioning and quality of partnership in patients in cardiovascular rehabilitation--a gender perspective. Journal of Sexual Medicine. 2009;6(1):164-74.

21. Muller MJ, Ruof J, Graf-Morgenstern M, Porst H, Benkert O. Quality of partnership in patients with erectile dysfunction after sildenafil treatment. Pharmacopsychiatry. 2001;34(3):91-5. 22. Hicks LL, McNulty JK, Meltzer AL, Olson MA. Capturing the Interpersonal Implications of Evolved Preferences? Frequency of Sex Shapes Automatic, but Not Explicit, Partner Evaluations. Psychological Science. 2016;27(6):836-47.

23. Schroder KE, Carey MP, Vanable PA. Methodological challenges in research on sexual risk behavior: II. Accuracy of self-reports. Annals of behavioral medicine. 2003;26(2):104-23.

24. Haavio-Mannila E, Kontula O. Correlates of Increased Sexual Satisfaction. Arch Sex Behav. 1997;26(4):399-419. 
Running Head: CVD, sex and relationship satisfaction

Table 1 - Sample demographic and clinical characteristics (M (SD) for continuous data, $\mathrm{n}(\%)$ for categorical data), $N=201$.

\begin{tabular}{lccc}
\hline Characteristic & $\begin{array}{c}\text { Men } \\
(n=176,87.6 \%)\end{array}$ & $\begin{array}{c}\text { Women } \\
(n=25,12.4 \%)\end{array}$ & $\begin{array}{c}\text { Total } \\
(N=201)\end{array}$ \\
\hline Age & $61.3(9.6)$ & $58.7(9.5)$ & $60.9(9.6)$ \\
Highest Education Level & & & \\
None/primary & $43(24.4 \%)$ & $9(36 \%)$ & $52(25.9 \%)$ \\
Secondary & $71(40.3 \%)$ & $11(44 \%)$ & $82(40.8 \%)$ \\
Tertiary & $62(35.2 \%)$ & $5(20 \%)$ & $67(33.4 \%)$ \\
Marital Status & & & \\
Married/cohabiting & $162(92.05)$ & $24(96 \%)$ & $186(92.5 \%)$ \\
Widowed & $5(2.8 \%)$ & $1(4 \%)$ & $6(3 \%)$ \\
Separated/divorced & $6(3.4 \%$ & $0(0 \%)$ & $6(3 \%)$ \\
Never married & $3(1.5 \%)$ & $0(0 \%)$ & $3(1.5 \%)$ \\
Medical Diagnoses & & & \\
Angina & $64(36.4 \%)$ & $8(32 \%)$ & $72(35.8 \%)$ \\
Myocardial infarction & $101(57.4 \%)$ & $11(44 \%)$ & $112(55.7 \%)$ \\
High blood pressure & $92(52.3 \%)$ & $13(52 \%)$ & $105(52.2 \%)$ \\
Stroke & $12(6.8 \%)$ & $2(8 \%)$ & $14(7 \%)$ \\
Diabetes* & $34(19.3 \%)$ & $0(0 \%)$ & $34(16.9 \%)$ \\
High cholesterol & $115(65.3 \%)$ & $15(60 \%)$ & $130(64.7 \%)$ \\
Depression & $25(14.2 \%$ & $6(24 \%)$ & $31(15.4 \%)$ \\
Anxiety* & $24(13.6 \%)$ & $9(36 \%)$ & $33(16.4 \%)$ \\
Cardiac procedures & & & \\
CABG & $31(17.6 \%)$ & $2(8 \%)$ & $33(16.4)$ \\
PTCA & $11(6.3 \%)$ & $0(0 \%)$ & $11(5.5 \%)$ \\
Stenting & $125(71.0 \%)$ & $17(68.0)$ & $142(70.6 \%)$ \\
Sexual Function Medication* & $45(25.6 \%)$ & $1(4.0 \%)$ & $46(22.9 \%)$ \\
\hline
\end{tabular}

Note. CABG: Coronary artery bypass graft. PTCA: Percutaneous Transluminal Coronary Angioplasty.

* Men and women were compared; significant differences at $p<.05$ are shown. 
Running Head: CVD, sex and relationship satisfaction

Table 2 - Prevalence (n, \%) of sexual problems before and after diagnosis/cardiac event for men and women $(N=201)$.

\begin{tabular}{lcccc}
\hline \multirow{2}{*}{ Problem } & \multicolumn{2}{c}{ Men } & \multicolumn{2}{c}{ Women } \\
& Before & After & Before & After \\
\hline Lacked interest in having sex & $42(23.9 \%)$ & $28(15.9 \%)$ & $9(36.0 \%)$ & $7(28.0 \%)$ \\
Did not find sex pleasurable & $25(14.2 \%)$ & $18(10.2 \%)$ & $7(28.0 \%)$ & $4(16.0 \%)$ \\
Unable to come to orgasm & $32(18.2 \%)$ & $32(18.2 \%)$ & $4(16.0 \%)$ & $2(18.0 \%)$ \\
Felt anxious about ability to & $10(5.7 \%)$ & $10(5.7 \%)$ & $3(12.0 \%)$ & $0(0 \%)$ \\
perform sexually & & & & \\
Men only... & $38(21.6 \%)$ & $29(16.5 \%)$ & & \\
$\quad$ Came to orgasm too quickly & $58(33.0 \%)$ & $57(32.4 \%)$ & & \\
$\quad$ Trouble maintaining an erection & & & $2(8.0 \%)$ & $2(8.0 \%)$ \\
Women only... & & & & \\
$\quad$ Pain during intercourse & & & & \\
$\quad$ Vaginal dryness & & & & \\
&
\end{tabular}


Running Head: CVD, sex and relationship satisfaction

Table 3 - Reports of relationship satisfaction among men and women $(N=201)$.

\begin{tabular}{lcccc}
\hline & $\begin{array}{c}\text { Possible } \\
\text { Range }\end{array}$ & $\begin{array}{c}\text { Actual } \\
\text { Range }\end{array}$ & Men & Women \\
& $1-5$ & $1-5$ & $4.10(0.88)$ & $3.44(1.19)$ \\
\hline Physical Satisfaction* & $1-5$ & $1-5$ & $4.05(0.79)$ & $4.16(0.75)$ \\
Emotional Satisfaction & $1-5$ & $2-5$ & $4.01(0.78)$ & $4.08(0.81)$ \\
Affectional Satisfaction & $1-5$ & $1-5$ & $3.61(1.06)$ & $3.96(0.67)$ \\
Communication Satisfaction & & & &
\end{tabular}


Running Head: CVD, sex and relationship satisfaction

Table 4 - Relationship satisfaction presented by perceived impact of CVD on sex

\begin{tabular}{lcccc}
\hline & $\begin{array}{c}\text { Better } \\
(\mathrm{n}=23)\end{array}$ & $\begin{array}{c}\text { Worse } \\
(\mathrm{n}=61)\end{array}$ & $\begin{array}{c}\text { No Change } \\
(\mathrm{n}=108)\end{array}$ & $\begin{array}{c}\text { Not Sure } \\
(\mathrm{n}=9)\end{array}$ \\
\hline Physical Satisfaction & $4.30(0.76)$ & $3.98(1.03)$ & $4.00(0.88)$ & $3.62(1.40)$ \\
Emotional Satisfaction & $4.13(0.91)$ & $3.96(0.88)$ & $4.07(0.68)$ & $4.37(0.74)$ \\
Affectional Satisfaction & $4.30(0.76)$ & $3.93(0.88)$ & $4.02(0.72)$ & $3.62(0.74)$ \\
Communication Satisfaction & $3.73(0.91)$ & $3.50(1.12)$ & $3.74(0.95)$ & $3.62(1.40)$ \\
\hline
\end{tabular}


Running Head: CVD, sex and relationship satisfaction

Table 5 - Relationship satisfaction presented by the presence or absence of sexual function problems after diagnosis

\begin{tabular}{lcc}
\hline & $\begin{array}{c}\text { At least 1 sexual function } \\
\text { problem present }\end{array}$ & $\begin{array}{c}\text { No sexual function problem } \\
\text { present } \\
M(S D)\end{array}$ \\
\hline Physical Satisfaction & $3.96(0.91)$ & $4.06(0.97)$ \\
Emotional Satisfaction & $4.02(0.97)$ & $4.09(0.77$ \\
Affectional Satisfaction & $4.00(0.83)$ & $4.02(0.74)$ \\
Communication Satisfaction & $3.60(1.02)$ & $3.71(1.01)$ \\
\hline
\end{tabular}


Running Head: CVD, sex and relationship satisfaction

Table 6 - Predictors of the domains of relationship satisfaction using multivariate multiple regression.

\begin{tabular}{lcccc}
\hline & $B$ & SE & $t$ & $95 \%$ CI for B \\
\hline $\begin{array}{l}\text { Physical Satisfaction } \\
\text { Constant }\end{array}$ & 5.92 & .47 & 12.46 & $(4.9,6.8)$ \\
$\quad$ Cumulative sexual problems & -0.07 & .04 & -1.61 & $(-0.16,0.02)$ \\
$\quad$ Gender & -0.73 & .19 & $-3.87^{*}$ & $(-1.11,-0.36)$ \\
$\quad$ Age & -0.01 & .01 & $-2.46^{*}$ & $(-0.03,-0.00)$ \\
Emotional Satisfaction & & & & \\
$\quad$ Constant & 4.21 & .42 & 9.95 & $(3.37,5.04)$ \\
Cumulative sexual problems & -0.04 & .04 & -0.99 & $(-0.12,0.04)$ \\
Gender & 0.09 & .17 & 0.58 & $(-0.23,0.43)$ \\
$\quad$ Age & -0.00 & .00 & -0.61 & $(-0.01,0.01)$ \\
Affectional Satisfaction & & & & \\
Constant & 4.47 & .42 & 10.52 & $(3.63,5.31)$ \\
Cumulative sexual problems & -0.02 & .04 & -0.51 & $(-0.10,0.06)$ \\
Gender & 0.05 & .17 & 0.30 & $(-0.28,0.39)$ \\
$\quad$ Age & -0.01 & .01 & -1.37 & $(-0.02,0.00)$ \\
Communication Satisfaction & & & & \\
Constant & 4.33 & .54 & 7.94 & $(3.25,5.40)$ \\
Cumulative sexual problems & -0.00 & .05 & -0.04 & $(-0.10,0.10)$ \\
Gender & 0.30 & .22 & 1.38 & $(-0.13,0.73)$ \\
Age & -0.02 & .01 & -2.16 & $(-0.03,-0.00)$ \\
\hline
\end{tabular}

Note. $\mathrm{SE}=$ Standard Error. $\mathrm{CI}=$ Confidence Interval.

$* p<.05$ 